\title{
Effects of Maturity of Coconut Shells on Gold Adsorption Efficiencies of Derived Activated Carbons*
}

\author{
${ }^{1}$ W. K. Buah, ${ }^{2}$ J. Darmey and ${ }^{3}$ Francisca Osei \\ ${ }^{1,3}$ University of Mines and Technology, Box 237, Tarkwa, Ghana. \\ ${ }^{2}$ Kwame Nkrumah University of Science and Technology, PMB, Kumasi, Ghana
}

Buah W. K., Darmey J. and Amoako Osei F. (2019), "Effects of Maturity of Coconut Shells on Gold Adsorption Efficiencies of Derived Activated Carbons", Ghana Mining Journal, Vol. 19, No. 2, pp. 50-54.

\begin{abstract}
Coconut shells are used as precursors for preparation of activated carbons. The shells could vary in terms of their maturity. The influence of the maturity of the shells on gold adsorption efficiencies of derived activated carbons (ACs) from gold dicyanide solution was investigated. The shells were pyrolysed at $900{ }^{\circ} \mathrm{C}$ and the resulting chars were activated in steam at the same temperature for different durations. Assessment of the properties of the derived ACs revealed that; the hardness, gold adsorption capacities and rates of gold adsorption of the ACs depended on the maturity of the shells. The more matured the shells the harder the AC. The relative hardness and gold adsorption rates of the mature coconut shells activated carbons, $H_{M}$ and $R_{M}$, respectively and those of the less mature shells, $H_{L}$ and $R_{L}$, respectively were in the order of $H_{M}>H_{L}$ and $R_{M}>R_{L}$. The relative hardness of the ACs derived from the more mature and less mature shells after 3 hrs activation were $99.3 \%$ and $94.0 \%$, respectively and the gold adsorption rates were $5.78 \mathrm{mg} \mathrm{Au} / \mathrm{hr} / \mathrm{g}$ and $4.95 \mathrm{mg} \mathrm{Au} / \mathrm{hr} / \mathrm{g}$, respectively. The adsorption rates and relative hardness depended on the duration of activation, where longer activation times resulted in increase in the adsorption rates and a decrease in relative hardness of the derived ACs.
\end{abstract}

Keywords: Adsorption, Activated Carbon, Coconut Shells, Maturity, Relative Hardness

\section{Introduction}

Activated carbons are carbonaceous materials having highly developed porous structure and a large internal surface area. Generally, activated carbons with higher surface areas exhibit higher adsorption capacities and their application also depends on their pore characteristics (Buah et al., 2014). Activated carbons have worldwide applications including removal of colour. For example, it is used for removal of colour from sugar syrup during commercial production of sugar and also for treatment of potable water, alcoholic beverage and fats (Buah et al., 2014; Mudoga et al., 2008; Satyawall and Bakakrishnan, 2007; Tennant and Mazyck, 2003). In the gold industry, activated carbon is used mainly to recover dissolved gold complexes from solutions (Zhonglin et al., 2017; Soleimani and Kaghazchi; 2008; Navarro et al., 2006; Yalcin and Arol, 2002). Activated carbon is achieved by removal of hydrogen rich fraction and other volatile constituents from the carbonaceous raw material to produce a porous residue with a large internal surface area (Buah and Kuma, 2012). There are two methods of activation for producing activated carbon from carbonaceous materials; these are chemical and physical activation processes.

Physical activation procedure involves a two-step process that is carbonisation followed by activation using steam, oxygen or carbon dioxide as activating agent (Mohd Iqbaldin et al., 2013; Yuen and
Hameed, 2009). However, in chemical activation procedure, carbonisation and activation processes occur in a single stage using chemicals such as potassium hydroxide, phosphoric acid and zinc chloride as activating agents (Mohd Iqbaldin et al., 2013; Ncibi et al., 2009).

Several researches have been conducted on the production of activated carbon from waste biomass such as coconut shells (Kajamani et al., 2018; Mohd Iqbaldin et al., 2013;). Though, the precursor material used for activated carbon production affect the pore structure of the derived activated products, investigations on the effects of maturity of the coconut shells on the derived activated carbons have not received attention. This paper investigates the effect of maturity of coconut shells on the relative hardness and gold adsorption properties of derived activated carbons.

\section{Resources and Methods Used}

\subsection{Preparation of the Activated Carbons}

Two samples of coconut shells of different maturity were collected. One sample was made up of matured coconut shells (M) (11 months old) and the other was less-matured coconut shells (L) (8 months old). The coconut shells were washed to remove dirt, sun dried, crushed and sieved to obtain the -2.8 $\mathrm{mm}+1.4 \mathrm{~mm}$ fractions, which were pyrolysed at $900{ }^{\circ} \mathrm{C}$, this temperature was measured with a thermocouple.The resulting chars obtained were physically activated in steam at the same temperature for various times, that is, $1 \mathrm{hr}, 2 \mathrm{hrs}$ and 
$3 \mathrm{hrs}$ activation times. The steam dosage rate was $0.02 \mathrm{ml} / \mathrm{min} / \mathrm{g}$.

\subsection{Adsorption Test}

A $0.2 \mathrm{~g}$ sample of activated carbon produced from each precursor after the various duration of activation with initial size range of $-2.8 \mathrm{~mm}+1.4$ $\mathrm{mm}$ were placed into bottles containing $200 \mathrm{~mL}$ of $7.2 \mathrm{mg} / \mathrm{L}$ gold solution. The bottles were placed on rollers for 27 hours. A $0.2 \mathrm{~g}$ of a commercial activated carbon, Norit RO 3515 was also subjected to the same procedure. Samples of the solution were taken at various times, that is, 3, 6, 9, 12, 15, 18, 21, 24 and 27 hours and analysed for gold concentration using a Varian Fast Sequential Atomic Adsorption Spectrophotometer (Varian AA240FS).

\subsection{Hardness Test}

A $2 \mathrm{~g}$ sample of activated carbon produced from each precursor after the various duration of activation with initial size range of $-2.8 \mathrm{~mm}+1.4$ $\mathrm{mm}$ were placed in a pan with a stainless steel ball and subjected to a combined rotating action for the same period of time. The particle disintegration is measured by determining the weight of carbons retained on a $0.707 \mathrm{~mm}$ sieve. A sample of a reference activated carbon, Norit RO 3515 was also subjected to the same procedure and the relative hardness of each activated carbon was calculated using:

$$
\text { Re lative Hardness }=\frac{W}{W_{r}} \times 100 \%
$$

Where, $W$ represents weight of the test activated carbon retained on $0.707 \mathrm{~mm}$ screen; $W_{r}$ represents weight of the reference activated carbon retained on the $0.707 \mathrm{~mm}$ screen.

\section{Results and Discussion}

\subsection{Adsorption Performance}

Adsorption of gold from gold di-cyanide solution with initial concentration of $7.2 \mathrm{mg} / \mathrm{L}$, by the commercial activated carbon and the activated carbons derived from the matured coconut shells (M) and less-mature coconut shells (L) after various duration of activation, is presented in Figs. 1 to 3.

In Figs. 1, 2 and 3 the reference AC performed better than the derived ACs produced from $\mathrm{M}$ and $\mathrm{L}$ at $1 \mathrm{hr}, 2 \mathrm{hrs}$ and $3 \mathrm{hrs}$ activation time. This is an indication that the derived activated carbons are not as active as the commercial activated carbon and therefore the need to optimise the processs variables, such as the activation time, and temperature, to enhance activation of the test precursors.

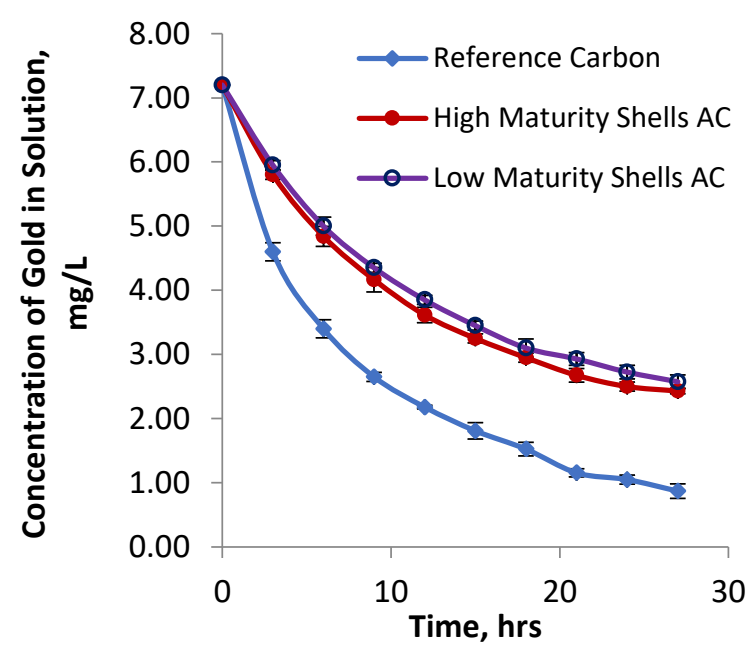

Fig. 1 Recovery of Gold from Solution by the Activated Carbons obtained after $1 \mathrm{hr}$ Activation and the Reference Activated Carbon

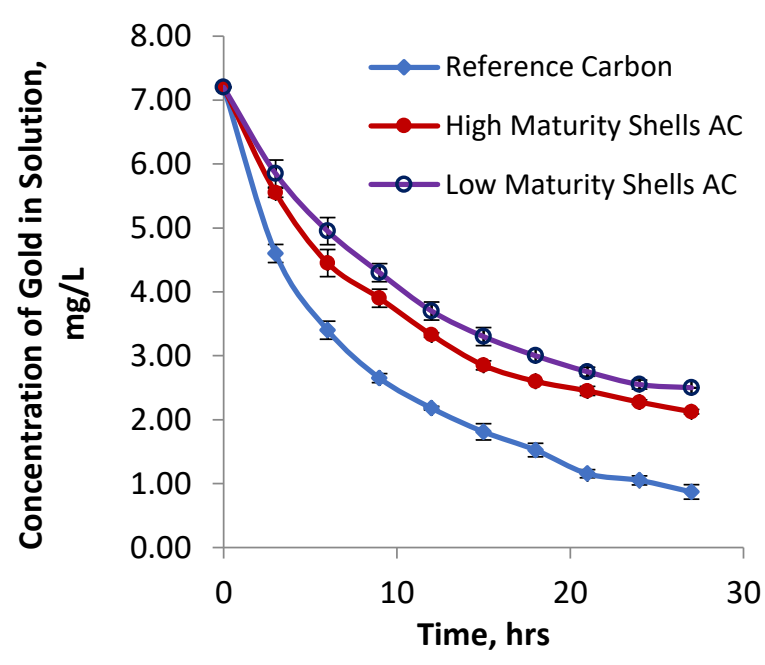

Fig. 2 Recovery of Gold from Solution by the Activated Carbons obtained after 2 hrs Activation and the Reference Activated Carbon 


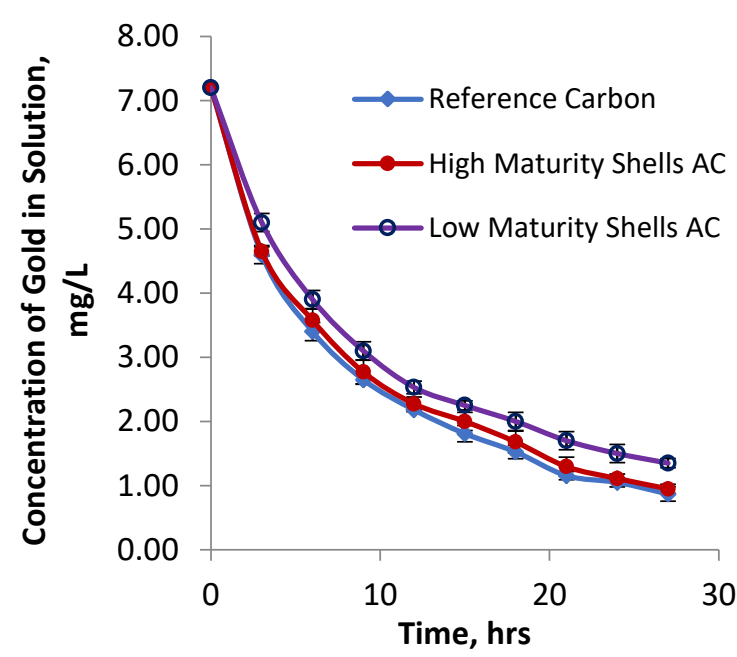

Fig. 3 Recovery of Gold from Solution by the Activated Carbons obtained after 3 hrs Activation and the Reference Activated Carbon

Based on the results in Figs. 1, 2 and 3 the percentage adsorption of gold by the AC derived were determined. After $27 \mathrm{hrs}$ of contact with the solution gold adsorption was $87.92 \%(31.65 \mathrm{mg}$ $\mathrm{Au} / \mathrm{g} \mathrm{C}), 66.25 \%$ (23.85 mg Au/g C) and $64.24 \%$ (23.13 $\mathrm{mg} \mathrm{Au} / \mathrm{g} \mathrm{C}$ ) for the reference carbon, the AC derived after $1 \mathrm{hr}$ activation of the matured and less mature coconut shells, respectively. For the AC produced after two hours of activation the gold adsorption was $70.49 \%$ (25.38 mg Au/g C) and $64.58 \%$ (23.5 mg Au/g C) for of the matured and less mature coconut shells, respectively. Similar trend occurred for $3 \mathrm{hrs}$ activation time, ACs derived from $\mathrm{M}$ had $86.61 \%$ (31.25 mg Au/g C) gold adsorption, which was greater than the gold adsorption of ACs derived from L, 81.25\% (29.25 $\mathrm{mg} \mathrm{Au} / \mathrm{g} \mathrm{C}$ ). From the results in Figs. 1 to 3, graphs of $t /(x / m)$ against time were plotted in Figs. 4 to 6 and the R-values were determined from the plots using eq. (2). The R-values of the derived ACs are presented in Table 1.

$\frac{t}{x / m}=\frac{1}{M} t+\frac{1}{R}$

where, $\mathrm{x} / \mathrm{m}$ represent the carbon loading in $\mathrm{mg} \mathrm{Au} / \mathrm{g}$ of carbon, $t$ is the time, $\mathrm{M}$ and $\mathrm{R}$ are reciprocal of the slope and the intercept at $\mathrm{t}=0$.

A higher R-value of a carbon indicates faster adsorption, implying less gold loss at the plant, as stated by Yalcin and Arol (2002). From Table 1, ACs from $\mathrm{M}$ have a higher R-value than ACs from $\mathrm{L}$ no matter the activation time.

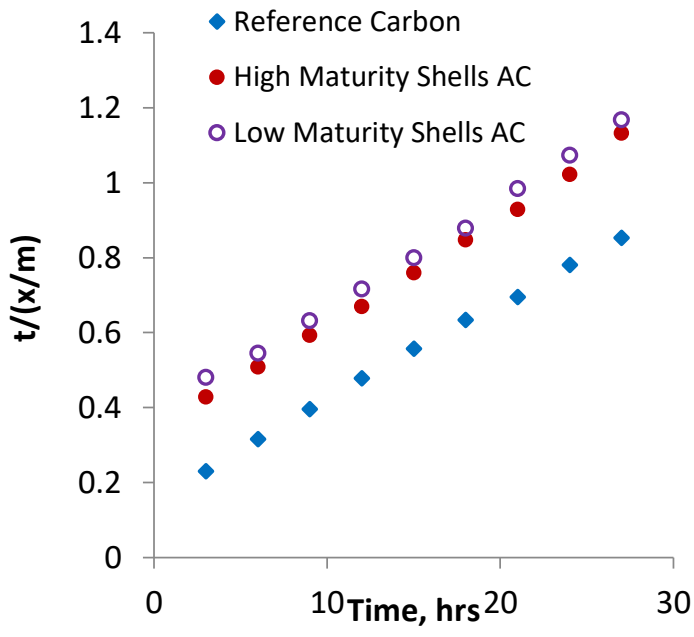

Fig 4 Adsorption Rate of ACs obtained after 1 Hour Activation

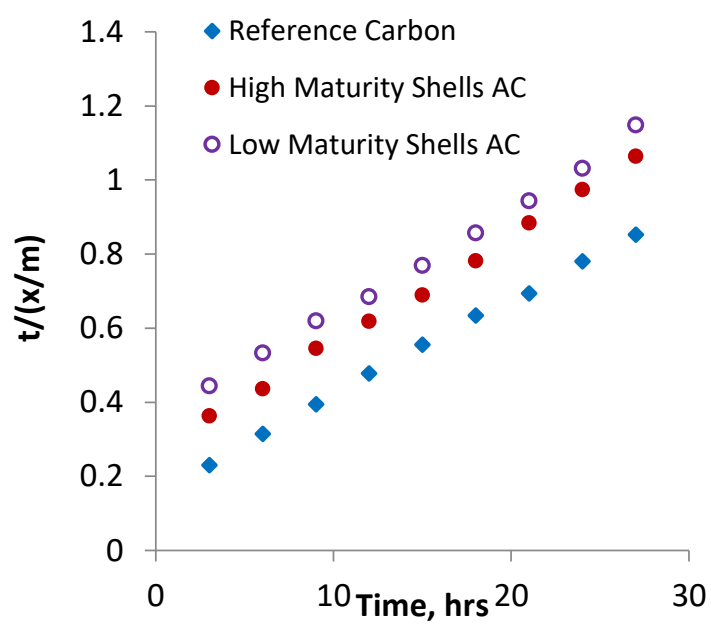

Fig. 5 Adsorption Rate of ACs Obtain after 2 Hours Activation

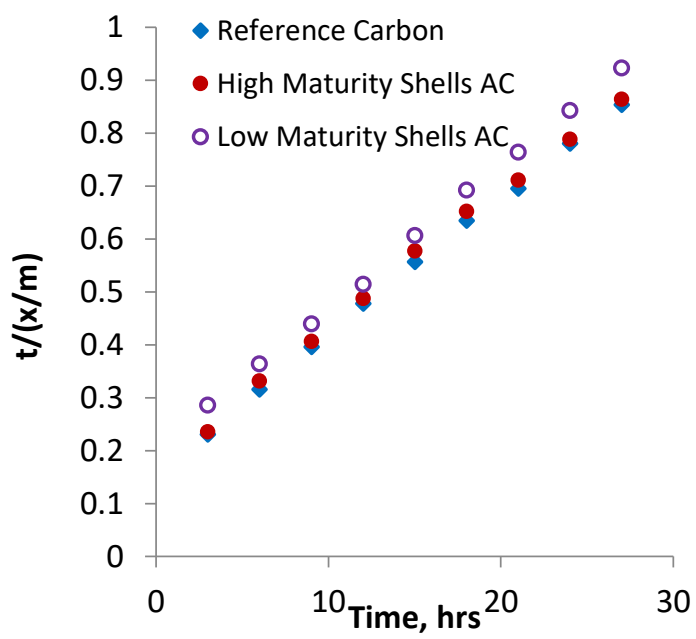

Fig 6 Adsorption Rate of ACs obtained after 3 Hours Activation 
Table 1 R-values of ACs Produced

\begin{tabular}{|c|c|c|c|c|c|c|}
\hline $\begin{array}{c}\text { Duration of } \\
\text { Activation }\end{array}$ & \multicolumn{2}{|c|}{ 1 Hour } & \multicolumn{2}{|c|}{ 2 Hours } & \multicolumn{2}{c|}{3 Hours } \\
\hline $\begin{array}{c}\text { Shell } \\
\text { Maturity }\end{array}$ & M & L & M & L & M & L \\
\hline $\begin{array}{c}\text { R-Value, } \\
\text { mg Au/hr/g }\end{array}$ & 3.01 & 2.67 & 3.72 & 2.82 & 5.78 & 4.95 \\
\hline
\end{tabular}

\subsection{Hardness}

The hardness of ACs produced from $\mathrm{M}$ and $\mathrm{L}$ at 1 $\mathrm{hr} 2 \mathrm{hrs}$ and $3 \mathrm{hrs}$ activation times are represented by Fig. 7 .

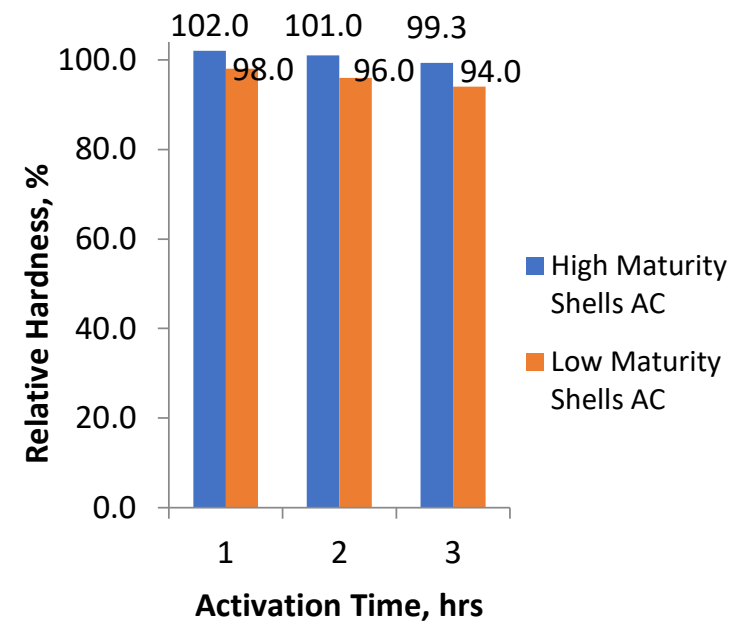

Fig. 7 Relative Hardness of Activated Carbons Obtained after $1 \mathrm{hr}, 2 \mathrm{hrs}$ and 3 hrs Activation

$\mathrm{AC}$ from $\mathrm{M}$ is harder than $\mathrm{AC}$ from $\mathrm{L}$, with $\mathrm{AC}$ from $M$ having $102 \%, 101 \%$ and $99.3 \%$ relative hardness after $1 \mathrm{hr}, 2 \mathrm{hrs}$ and $3 \mathrm{hrs}$ activation times respectively. AC from L had 98\%, 96\% and 94\% relative hardness at $1 \mathrm{hr}, 2 \mathrm{hrs}$ and $3 \mathrm{hrs}$ activation times respectively. The decrease in hardness of the ACs with increased activation time is due to generation of more pores in the carbons as the activation time increases.

\section{Conclusions}

The activated carbon produced from the matured coconut shells adsorbed better than the activated carbon produced from less matured coconut shells. Also, activated carbon produced from the matured coconut shells was harder than the activated carbon produced from less matured coconut shells. The adsorption rates and relative hardness also depended on the duration of activation, where longer activation times resulted in increase in the adsorption rates and a decrease relative hardness of the derived ACs.

\section{References}

Buah, W. K., Kuma, J. S. Y. and Williams, P. T (2014), "Activated Carbon Prepared in a Novel Gas Fired Static Bed Pyrolysis Gasification/Activation Reactor for Gold DiCyanide Adsorption", 3rd UMaT Biennial International Mining and Mineral Conference, pp. 243-250.

Buah, W. K. and Kuma, J. S. Y. (2012), "Properties of Activated Carbon Prepared from Coconut Shells in Ghana", Ghana Mining Journal, pp. 51 $-55$.

Zhonglin, D., Tao, J., Bin, X., Yongbin, Y. and Qian, L. (2017), "Recovery of Gold from Pregnant Thiosulfate Solutions by the Resin Adsorption Technique", Metals 2017, pp. 7.

Mohd Iqbaldin M. N, Khudzir I., Mohd Azlan M. I., Zaidi A. G., Surani B. and Zubri Z. (2013), "Properities of Coconut Shell Activaed Carbon”, Journal of Tropical Forest Science, Vol. 25, No. 4, pp. 497-503.

Mudoga, H. L., Yucel, H., and Kincal, N. S. (2008), "Decolorization of sugar syrups using commercial and sugar beet pulp based activated carbons", Bioresource Technology, Vol. 99, No. 9 , pp. $3528-3533$.

Navarro, M. V., Seaton, N. A., Mastral, A. M., and Murillo, R. (2006), "Analysis of the evolution of the pore size distribution and the pore network connectivity of a porous carbon during activation", Carbon, Vol. 44, pp. 2281 - 2288.

Ncibi M. C., Jeanne-Rose V., Mahjoub B., JeanMarius C., Lambert J., Ehrhardt J. J., Bercion Y., Seffen M. and Gaspard S. (2009). "Preparation and characterization of raw chars and physically activated carbons derived from marine Posidonia oceanica (L.) fibres", Journal of Hazardous Material, Vol. 165, pp. 240-249.

Kajamani, R., Vinoth Kumar, B., Sujith, A. and Karthick, E. (2018), "Activated Carbon Production from Waste Biomass", International Journal of Engineering and Technology, Vol. 7, No. 3.34, pp. 345-348.

Satyawall, Y. and Balakrishnan, A. (2007), "Removal of color from biomethanated distillery spentwash by treatment with activated carbons", Bioresource Technology, Vol. 98, No. 14, pp. 2629 - 2635.

Soleimani, M. and Kaghazchi, T. (2008), "Activated hard shell of apricot stones: A promising adsorbent in gold recovery", Chinese Journal of Chemical Engineering, Vol. 16, No. 1, pp. 112 - 118.

Tennant, M. F. and Mazyck, D. W. (2003), "Steampyrolysis activation of wood char for 
superior odorant Removal", Carbon, Vol. 41, pp. 2195 - 2202.

Yalcin, M. and Arol, A. I. (2002), "Gold cyanide adsorption characteristics of activated carbon of non-coconut shell origin", Hydrometallurgy, Vol. 63, pp. 201- 206.

Yuan G. H., Jiang Z. H., Aramat M. \& Gao Y. Z. (2005, "Electrochemical behavior of activatedcarbon capacitor material loaded with nickel oxide" Carbon, Vol. 4, pp. 2913-2917.

\section{Authors}

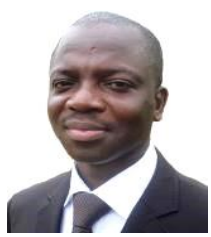

W. K. Buah is currently a Professor at the University of Mines and Technology, Tarkwa, Ghana. He holds a PhD in Waste Processing Engineering from the University of Leeds, Leeds, UK and a Master of Science Degree in Minerals Processing Engineering from the Mining Institute of Krivoy Rog, Krivoy Rog, Ukraine. He is a member of the Society for Mining, Metallurgical and Exploration Engineers (SME) and the Ghana Institution of Engineers (GhIE). His current research interests include mineral processing and extractive metallurgy, waste management, pyrolysis-gasification of wastes and biomass to produce valuable products, including activated carbon for gold adsorption.

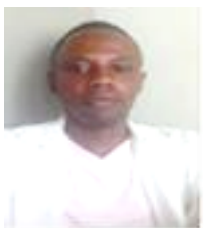

J. Darmey is currently an unemployed MSc Graduate. He holds a Master of Science Degree in Chemical Engineering from Kwame Nkrumah University of Science and Technology, Kumasi, Ghana and a BSc. in Minerals Engineering from University of Mines and Technology, Tarkwa, Ghana. His current research interests include mineral processing and extractive metallurgy (ferrous metallurgy), waste management, pyrolysis-gasification of wastes and biomass to produce valuable products, including activated carbon for gold adsorption.

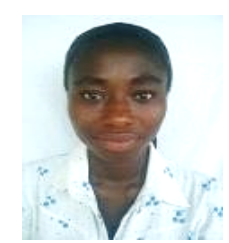

F. Amoako Osei is currently an unemployed BSc. Graduate. She holds a BSc degree in Minerals Engineering from the University of Mines and Technology, Tarkwa, Ghana. Her research interest includes, mineral processing and pyrolysis-gasification of biomass 